\title{
Proceeding
}

Supplementary Issue: Spring Conferences of Sports Science. 15th Convention and Workshop of the International Network of Sport and Health Science, 5-8 June 2019. University of Las Palmas de Gran Canaria, Las Palmas de Gran Canaria, Spain.

\section{Spanish Winter Olympic athlete's communication on Instagram}

\author{
JAVIER ABUÍN-PENAS ${ }^{1}$, MARÍA JOSÉ MARTÍNEZ-PATIÑO, MARÍA ISABEL MÍGUEZ-GONZÁLEZ \\ University of Vigo, Spain
}

\begin{abstract}
Social media have become an increasingly popular tool for athletes to share content with their followers. This study's purpose was to contribute to the understanding of athlete communication on Instagram by focusing on the communication strategies of the Spanish Winter Olympic team during 2018, when the PyeongChang Olympic Games were held. Content analysis was performed on 990 Instagram posts collected through the Instagram Scraper tool, analysing a wide variety of data such as the number of likes and comments, the format of the publication, the use hashtags or the text of each post. The data was processed in Excel. Although the analysis is in process, some preliminary results can be provided. All the 13 athletes from the Spanish Olympic team who participated in the PyeongChang Olympic Winter Games use Instagram. His followers range from 1,413 by Imanol Rojoy to 259,432 by Javier Fernández. In 2018 they published on Instagram between 24 and 191 posts, a total of 990 contributions ( $90.61 \%$ of images and $9.39 \%$ of videos), which generated more than 2 and a half million likes and almost 40,000 comments. Findings from these preliminary results suggest that, in general, Instagram is revealed as an effective tool for Olympic athletes when it comes to generating visibility among their audiences and fan engagement increases during the celebration of an international mega event as the Olympic Winter Games. Keywords: Social media; Sport communication; Self-presentation; Olympism.
\end{abstract}

\section{Cite this article as:}

Abuín-Penas, J., Martínez-Patiño, M.J., \& Míguez-González, M.I. (2019). Spanish Winter Olympic athlete's communication on Instagram. Journal of Human Sport and Exercise, 14(4proc), S780-S791. doi:https://doi.org/10.14198/ihse.2019.14.Proc4.40

Corresponding author. Facultad de Ciencias de la Educación y del Deporte (office 218) Campus A Xunqueira s/n. - 36005, Pontevedra, Spain.

E-mail: jabuin@uvigo.es

Supplementary Issue: Spring Conferences of Sports Science. 15th Convention and Workshop of the International Network of Sport and Health Science, 5-8 June 2019. University of Las Palmas de Gran Canaria, Las Palmas de Gran Canaria, Spain. JOURNAL OF HUMAN SPORT \& EXERCISE ISSN 1988-5202

(C) Faculty of Education. University of Alicante

doi:10.14198/jhse.2019.14.Proc4.40

S780 | 2019| Proc4 | VOLUME 14

C 2019 University of Alicante 


\section{INTRODUCTION}

In sport, as in many other fields, organizations have been utilizing social media to maximize their communication efforts and to reach their audiences. Additionally, athletes and fans are using social media as a way to communicate their own message without the need of marketing or public relations figures. Social media has allowed athletes to have a much closer relationship with their fans by showing their day-to-day lives, their feelings, or their ideas about everything they want. They also have the opportunity to see the feedback of their audience and interact with them in the easiest way ever (Pegoraro, 2010).

The use of social media in sports has been deeply studied in recent years in Spain. Sotelo (2012) analysed the use of social media by Spanish football clubs and explained that clubs are not only in a testimonial way in social media, they are part of them. Other studies such as Olabe (2012) or Lobillo and Muñoz (2016) also analysed the use of social media by the biggest Spanish football clubs, focusing on how they used Twitter to promote the internationalization of their brand. Recent research, as López de Ayala, Fernández and CatalinaGarcía (2018), analyse how golf clubs transmit different types of messages (educational, lifestyle, contests, questions or raffles), including messages that directly appeal to the interlocutor, such as greetings, which are more effective in generating interactivity (López de Ayala, Catalina-García and Fernández, 2018).

However, not only sports organizations, such as the football clubs previously mentioned, the ones that are using social media, but also the athletes are using them in an individual way. In this sense, Cano-Tenorio and Paniagua-Rojano (2017), by analysing how being on Twitter help elite athletes, found that communication on social media allows elite athletes to differentiate themselves from others, which it is fundamental to succeed and to connect with their audiences.

In the world of social media, Instagram is the third most present social network in the minds of Internet users (behind Facebook and Twitter), it is also the network that has increased most in users in Spain in 2018 compared to the previous year and it is also where the frequency of visits has increased the most, according to IAB Spain (2018). In addition, according to this same study, Instagram is, along with WhatsApp and YouTube, one of the three social media preferred by generation $Z$ (from 16 to 23 years old right now). In sport in particular, it is becoming an increasingly popular tool for sharing visual content, according to Anagnostopoulos et al. (2018), who highlight that the use of Instagram by sport organizations facilitates cobranding and provides fans with a more active role in the process of building the brand. Likewise, in a research on golf, Davies and Mudrick (2017) suggest that the use of Instagram could respond to a greater variety of reasons than the use of other social platforms such as Facebook and Twitter, which would use less the promotional fact.

From this perspective, several international studies have tried to address specific aspects of the use of Instagram by athletes. Geurin-Eagleman and Burch (2016) show how athletes use this social network as a tool to build their personal image, finding a relation between the engagement with the variety of photos and noting that sexually suggestive posts reach a greater number of likes and comments. Likewise, Kim and Hull (2017) states that baseball team followers on Instagram engage more (with comments and likes) to posts related to sports issues than to those that have to do with social or business issues. Other recent studies focus on specific aspects such as the use of Instagram to challenge or reinforce gender stereotypes (Pegoraro et al., 2018) or strategies to attract Hispanic followers, in the case of baseball, through the use of language (Hull et al., 2018). 
As social media give new communication opportunities to athletes, increasingly decentralizing the control of information, this research purpose was to contribute to the understanding of athlete's communication on Instagram by focusing on the communication strategies of the Spanish Winter Olympic team during 2018, when the PyeongChang Olympic Games were held.

\section{MATERIAL AND METHODS}

Trying to obtain a representative sample of Spanish elite athletes, it was decided to take as reference the whole Olympic team that went to represent Spain at the PyeongChang 2018 Olympic Winter Games. The 2018 Winter Olympics, officially known as the XXIII Olympic Winter Games and commonly known as PyeongChang 2018, was an international winter multi-sport event that was held between 9 and 25 February 2018 in PyeongChang County, (South Korea). This competition was selected because it was the most recent mega sporting event at the time when the research was carried out.

The 2018 Winter Olympics featured 102 events over 15 disciplines in 7 different sports, where a total of 13 athletes (11 men and 2 women) who participated in 5 different sports represented the Spanish Olympic team. The team members were:

- In figure skating: Javier Fernández (male), Felipe Montoya (male) and Sara Hurtado / Kirill Khaliavin (dance on ice).

- $\quad$ In Skeleton: Ander Mirambell (male).

- In Snowboard: Queralt Castellet (half-pipe), Lucas Eguibar (Cross Country), Regino Hernández (Cross Country) and Laro Herrero (Cross Country).

- $\quad$ In alpine skiing: Juan del Campo and Joaquim Salarich.

- $\quad$ In Cross-country skiing: Imanol Rojo and Martí Vigo del Arco.

In this edition, Spain won two bronze medals (Regino Hernández and Javi Fernández) and an Olympic diploma of 7th place (Queralt Castellet), thus breaking a 26-year drought without having a winter sports medallist.

The study was temporarily limited to 2018, year in which all the Instagram publications of the 13 selected athletes were collected, using the Instagram Scraper ${ }^{1}$ tool, developed by the Digital Methods Initiative (DMI). This tool interfaces with the API of Instagram to retrieve overviews of posts for a given set of usernames or hashtags, allowing you to download a CSV file containing the metadata for all scraped posts. The variety of data displayed includes username, text of the publication, post type (image or video), link to the publication, link to multimedia content, date, number of likes, number of comments, hashtags used and location, among others.

All the data was processed in several spreadsheets using Excel looking for different crosses of interest among the variables, we also added searches of relevant keywords in terms of relations with the public.

\footnotetext{
1 "Instagram Scraper" tool from the Digital Methods Initiative: https://wiki.digitalmethods.net/Dmi/ToolDatabase?cat=DeviceCentric\&subcat=Instagram
} 


\section{RESULTS}

Table 1. Type and resources data used

\begin{tabular}{|c|c|c|c|c|c|c|c|c|c|c|c|}
\hline \multirow[t]{2}{*}{ Athlete } & \multirow[t]{2}{*}{$\begin{array}{l}\text { Number } \\
\text { of posts }\end{array}$} & \multicolumn{2}{|c|}{ Photos } & \multicolumn{2}{|c|}{ Videos } & \multicolumn{2}{|c|}{ Posts with hashtags } & \multicolumn{2}{|c|}{ Posts with mentions } & \multicolumn{2}{|c|}{ Posts with emoticons } \\
\hline & & $\mathrm{n}$ & $\% *$ & $\mathrm{n}$ & $\%^{*}$ & $\mathrm{n}$ & $\%^{*}$ & $\mathrm{n}$ & $\% *$ & $\mathrm{n}$ & $\%^{*}$ \\
\hline Ander Mirambell & 50 & 41 & $82 \%$ & 9 & $18 \%$ & 49 & $98 \%$ & 31 & $62 \%$ & 29 & $58 \%$ \\
\hline Felipe Montoya & 145 & 132 & $91 \%$ & 13 & $9 \%$ & 72 & $50 \%$ & 54 & $37 \%$ & 90 & $62 \%$ \\
\hline Imanol Rojo & 59 & 57 & $97 \%$ & 2 & $3 \%$ & 43 & $73 \%$ & 28 & $47 \%$ & 47 & $80 \%$ \\
\hline Javier Fernández & 91 & 76 & $84 \%$ & 15 & $16 \%$ & 64 & $70 \%$ & 50 & $55 \%$ & 43 & $47 \%$ \\
\hline Juan del Campo & 93 & 86 & $92 \%$ & 7 & $8 \%$ & 85 & $91 \%$ & 61 & $66 \%$ & 92 & $99 \%$ \\
\hline Kirill Khaliavin & 55 & 54 & $98 \%$ & 1 & $2 \%$ & 20 & $36 \%$ & 20 & $36 \%$ & 39 & $71 \%$ \\
\hline Laro Herrero & 24 & 20 & $83 \%$ & 4 & $17 \%$ & 21 & $88 \%$ & 19 & $79 \%$ & 19 & $79 \%$ \\
\hline Lucas Eguibar & 36 & 34 & $94 \%$ & 2 & $6 \%$ & 4 & $11 \%$ & 8 & $22 \%$ & 35 & $97 \%$ \\
\hline Marti Vigo & 38 & 36 & $95 \%$ & 2 & $5 \%$ & 9 & $24 \%$ & 9 & $24 \%$ & 31 & $82 \%$ \\
\hline Queralt Castellet & 108 & 98 & $91 \%$ & 10 & $9 \%$ & 35 & $32 \%$ & 41 & $38 \%$ & 84 & $78 \%$ \\
\hline Quim Salarich & 53 & 52 & $98 \%$ & 1 & $2 \%$ & 18 & $34 \%$ & 41 & $77 \%$ & 48 & $91 \%$ \\
\hline Regino Hernández & 47 & 44 & $94 \%$ & 3 & $6 \%$ & 9 & $19 \%$ & 14 & $30 \%$ & 44 & $94 \%$ \\
\hline Sara Hurtado & 191 & 167 & $87 \%$ & 24 & $13 \%$ & 191 & $100 \%$ & 128 & $67 \%$ & 188 & $98 \%$ \\
\hline TOTAL & 990 & 897 & $91 \%$ & 93 & $9 \%$ & 620 & $63 \%$ & 504 & $51 \%$ & 789 & $80 \%$ \\
\hline
\end{tabular}

Table 2. Following and follower's data

\begin{tabular}{lcccc}
\hline \multicolumn{1}{c}{ Athlete } & Posts & Followers (15/01/19) & Following (15/01/19) & Ratio followers / following \\
\hline Ander Mirambell & 50 & 3713 & 650 & 5.71 \\
Felipe Montoya & 145 & 3515 & 1498 & 2.35 \\
Imanol Rojo & 59 & 1413 & 848 & 7.67 \\
Javier Fernández & 91 & 259432 & 595 & 326.33 \\
Juan del Campo & 93 & 5356 & 482 & 10.36 \\
Kirill Khaliavin & 55 & 4941 & 950 & 10.25 \\
Laro Herrero & 24 & 5030 & 1755 & 5.29 \\
Lucas Eguibar & 36 & 40054 & & 22.82 \\
& & & VOLUME 14| Proc4 | 2019| S783
\end{tabular}




\begin{tabular}{lcccc} 
Marti Vigo & 38 & 5434 & 2352 & 2.31 \\
Queralt Castellet & 108 & 26909 & 879 & 30.61 \\
Quim Salarich & 53 & 3845 & 1113 & 3.45 \\
Regino Hernández & 47 & 11767 & 473 & 24.88 \\
Sara Hurtado & 191 & 12012 & 1337 & 8.98 \\
\hline TOTAL & 990 & 383421 & 13649 & 1049.92 \\
AVERAGE & 76.15 & 29493.92 & 879 & \\
MEDIAN & 55 & 5356 & & \\
\hline
\end{tabular}

Table 3. Public interaction

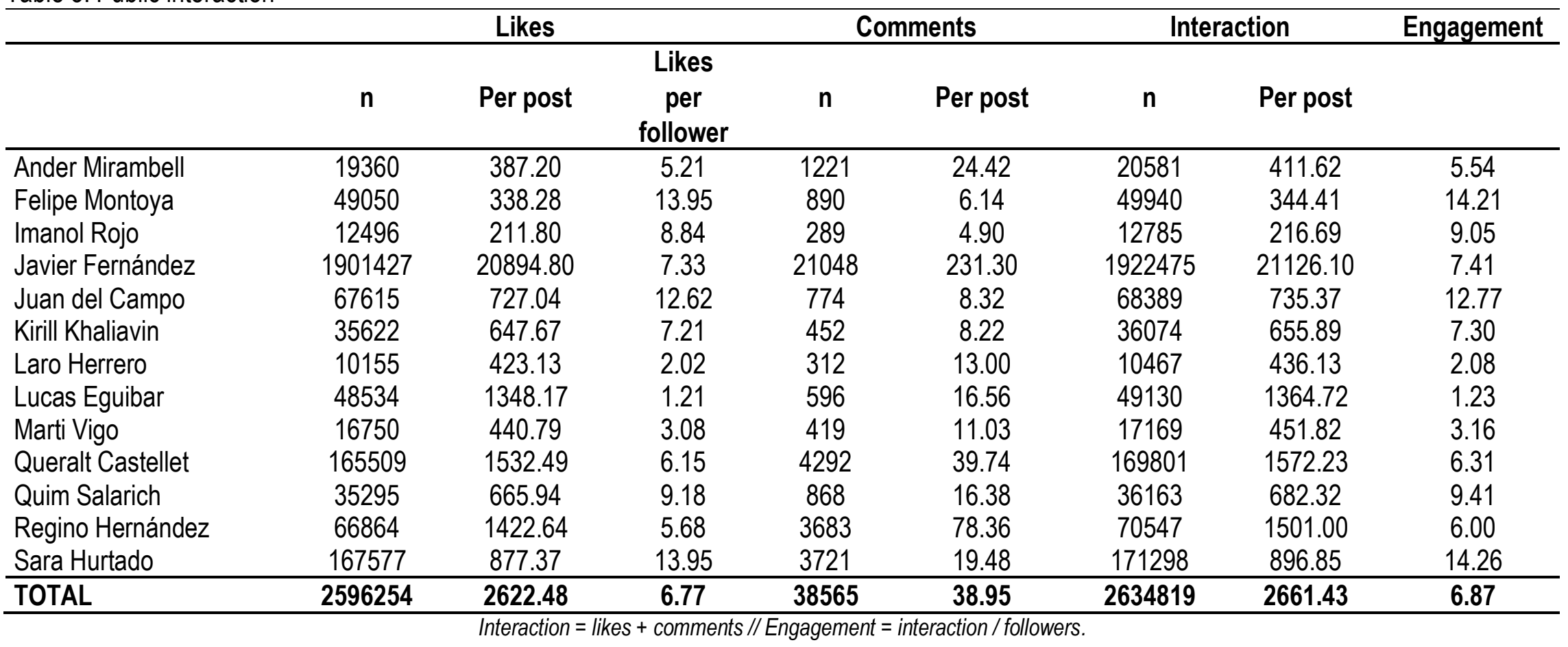


Table 4. Engagement and type or resources used

\begin{tabular}{|c|c|c|c|c|c|}
\hline & Posts & Total likes & Average likes & Total Comments & Average Comments \\
\hline Photo Posts & 897 & 2340229 & 2608.9509 & 33773 & 37.6511 \\
\hline Video Posts & 93 & 256025 & 2752.957 & 4792 & 51.5269 \\
\hline Posts with Hashtags & 620 & 1742793 & 2810.9565 & 25629 & 41.3371 \\
\hline Posts without Hashtags & 370 & 853461 & 2306.6514 & 12936 & 34.9622 \\
\hline Posts with Mentions & 504 & 1307310 & 2593.869 & 20607 & 40.8869 \\
\hline Posts without Mentions & 486 & 1288944 & 2652.1481 & 17958 & 36.9506 \\
\hline Posts with Emoticons & 789 & 1577295 & 1999.1064 & 28038 & 35.5361 \\
\hline Posts without Emoticons & 201 & 1018959 & 5069.4478 & 10527 & 52.3731 \\
\hline
\end{tabular}

Table 5. Average likes timing

\begin{tabular}{|c|c|c|c|c|c|}
\hline Athlete & Posts & Pre Olympics & Olympics & Post Olympics & No Olympics \\
\hline Ander Mirambell & 50 & 455.25 & 1004.00 & 355.50 & 324.1891 \\
\hline Felipe Montoya & 145 & 373.21 & 519.65 & 419.92 & 288.1875 \\
\hline Imanol Rojo & 59 & 183.75 & 320.33 & 239.57 & 195.4474 \\
\hline Javier Fernández & 91 & 23784.50 & 48140.75 & 25185.57 & 18781.865 \\
\hline Juan del Campo & 93 & 1002.56 & 1229.00 & 853.00 & 640.2778 \\
\hline Kirill Khaliavin & 55 & 611.68 & 844.80 & 679.60 & 520.1667 \\
\hline Laro Herrero & 24 & 504.33 & 689.00 & 433.50 & 376.2941 \\
\hline Lucas Eguibar & 36 & & & & 1348.1667 \\
\hline Marti Vigo & 38 & 506.50 & 612.17 & 459.00 & 387.08 \\
\hline Queralt Castellet & 108 & 2033.90 & 2824.50 & 1694.82 & 1352.8395 \\
\hline Quim Salarich & 53 & 980.60 & 1134.00 & 754.00 & 584.7317 \\
\hline Regino Hernández & 47 & 483.50 & 2703.29 & 2236.83 & 1086.2 \\
\hline Sara Hurtado & 191 & 913.18 & 1350.06 & 970.21 & 801.94 \\
\hline TOTAL & 990 & 2160.02 & 3191.86 & 2797.94 & 2590.89 \\
\hline
\end{tabular}


Table 6. Average comments timing

\begin{tabular}{|c|c|c|c|c|c|}
\hline Athlete & Posts & Pre Olympics & Olympics & Post Olympics & No Olympics \\
\hline Ander Mirambell & 50 & 41.38 & 98.67 & 9.00 & 15.57 \\
\hline Felipe Montoya & 145 & 7.37 & 11.41 & 5.46 & 5.05 \\
\hline Imanol Rojo & 59 & 7.63 & 15.17 & 2.71 & 3.11 \\
\hline Javier Fernández & 91 & 466.00 & 1199.00 & 150.29 & 167.62 \\
\hline Juan del Campo & 93 & 26.11 & 23.17 & 5.33 & 5.11 \\
\hline Kirill Khaliavin & 55 & 8.83 & 12.93 & 7.70 & 5.33 \\
\hline Laro Herrero & 24 & 26.33 & 22.50 & 6.00 & 10.35 \\
\hline Lucas Eguibar & 36 & & & & 16.56 \\
\hline Marti Vigo & 38 & 29.75 & 31.83 & 6.00 & 3.64 \\
\hline Queralt Castellet & 108 & 125.50 & 71.00 & 29.09 & 28.28 \\
\hline Quim Salarich & 53 & 67.00 & 58.33 & 13.75 & 7.39 \\
\hline Regino Hernández & 47 & 11.00 & 129.00 & $378.67^{*}$ & 45.47 \\
\hline Sara Hurtado & 191 & 21.24 & 27.76 & 16.47 & 18.66 \\
\hline TOTAL & 990 & 58.67 & 86.11 & 47.32 & 29.02 \\
\hline
\end{tabular}

${ }^{*}$ Amount favoured by a Instagram raffle based on comments.

Table 7.100 posts with more interaction

\begin{tabular}{lcccc}
\hline & \% videos & \% posts with hashtags & \% posts with mentions & \% posts with emoticons \\
\hline 100 posts with more likes & 15 & 65 & 53 & 78 \\
100 posts with more comments & 18 & 66 & 54 & 56 \\
\hline Total Posts & 9.4 & 62.63 & 50.91 & 79.7 \\
\hline
\end{tabular}




\section{Number, type and post resources used}

The 13 analysed athletes published in 2018 between 24 and 191 posts, adding a total of 990 contributions. More than $90 \%$ of posts are images, while only $9,4 \%$ are videos, with small oscillations depending on the athlete but all of them have a percentage of photos of more than $80 \%$.

Hashtags are present in more than $60 \%$ of the posts; athletes such as Sara Hurtado, Ander Mirambell or Juan del Campo use hashtags in more than $90 \%$ of their posts, while Lucas Eguibar and Regino Hernández only use them in less than $20 \%$ of their posts. The mentions are less used, they only appear in $50,9 \%$ of the posts, while the oscillations of use among athletes are similar, reaching a 79\% presence in Laro Herrero's posts and a 22\% presence in Lucas Eguibar's posts. The majority of athletes do employ emoticons frequently, present in more than $80 \%$ of the total of the posts in the sample; the cases of Javier Fernández, who incorporate emoticons in only $47 \%$ of his posts, is especially significant for being the only athlete that uses emoticons in less than half of his posts (table 1).

\section{Following and follower's data}

As regards the followers, they range between 1.413 from Inmanol Rojo and 25.9432 from Javier Fernandez, with a median of 5.356 followers. The following median is 879 and the number of following barely exceeds 2.300 in the best case (Marti Vigo). The overall ratio between followers and followers is almost 28 followers for each follow-up and there is no significant correlation between the two variables $(r=-0.09)$. In the same way, the correlation between the number of publications and the number of followers is almost inexistent $(r$ $=0.09$ ) (Table 2).

\section{Public interaction}

With regard to the reception results, it should be noted that the set of post generated more than two and a half millions of likes, although almost two million (1.901.427) correspond only to the posts of Javier Fernández, while Laro Herrero exceeds scarcely 10.000. The oscillations are so important among athletes that the median of likes does not reach 50.000 . The total of likes per post exceeds 2.500 , although it oscillates, again, between the 211 of Inmanol Rojo and the more than 20.000 of Javier Fernández; The correlation between the number of publications of each athlete and the number of likes is 0.17 . The average of likes per follower is only 6,7 ; however, there is a very high correlation between the number of followers and the number of likes obtained $(r=0.99)$.

About the comments, almost 40.000 comments were generated. The athlete who accumulate more comments in their publications and also a higher average of comments per post is Javier Fernández. The average number of comments per post is almost 39 and the correlation between number of posts and number of comments is 0.22 . In addition, the correlation between followers and comments is high $(r=0.97)$.

The general interaction data (likes + comments) per post is 2.634 .819 , while the engagement data (interaction I followers) is 6,87 . The average engagement per athlete is, on the other hand, higher (7.6). While Javier Fernández is, by far, the athlete that generates more interaction in absolute terms and on average per post, the engagement is much higher in athletes such as Sara Hurtado, Felipe Montoya or Juan del Campo.

As interesting results, it can be highlighted that Sara Hurtado and Felipe Montoya, the two athletes that have produced the most posts during 2018 (191 and 145 posts respectively), are also the ones with better engagement (14,26 and 14,21 respectively) levels in Instagram. In addition, the correlation between the number of posts and the engagement is high $(r=0.81)$. 


\section{Relationship between interaction and the post type or resources used}

Regarding the relationship between the post type and the interaction, it is verified that photos obtain similar average of likes, while, videos have received a higher average of comments.

On the other hand, it has been observed that the posts that used hashtags (\#) obtained a little higher average of likes, reaching an average of 2810,96 likes per post, compared to the posts that did not use hashtags, which obtained an average of 2306,65 likes. In this case the result is similar when it comes to the average of comments, the posts that used hashtags received an average of 41,34 comments, in comparison with the posts that did not use hashtags, which received an average of 34,96 comments.

In the case of Instagram posts with mentions (@) barely get an average of 2593,87 likes compared to an average of 2652,15 likes in post without mentions. While the relationship when we refer to the average of comments is 40,89 in the posts with mentions and 36,95 in the posts without mentions.

On the impact that emoticons have, this research reveals that the publications with emoticons obtain an average of likes and comments (1999,11 and 35,54, respectively) lower in both cases than the average of likes and comments of the posts without emoticons (5069,45 and 52,37, respectively).

\section{Posts timing}

For the analysis of this section the athlete Lucas Eguibar was discarded, because he has no posts between January and July 2018, so there are only results of his activity on Instagram in the period called "No Olympics".

In terms of timing, it can be observed how the number of likes is much greater in posts made during the Olympic Games (from February 9 to February 25) compared to the publications made in the previous period to the Olympics (the previous 30 days), in the period immediately after (the following 30 days) or during the rest of the year. It should also be noted that the number of likes has been increased much higher in the case of athletes who had won medals such as Javier Fernández and Regino Hernández, who increased their average of likes by more than $100 \%$ and more than $400 \%$ respectively. While in the average of likes of the whole sample increases during the Olympic Games is almost $50 \%$.

In the case of comments, the situation is different although most athletes get more comments in their publications during the Olympic Games (as happened with the likes in this case the average of comments also increases almost 50\%), there are some exceptions such as Quim Salarich, Queralt Castellet, Laro Herrero or Juan del Campo who have received more comments in them prior to the Olympic Games posts (Pre Olympics). In this section, the case of Regino Hernández deserves a separate mention, this athlete obtained a much higher number of comments in the period after the Olympic Games (Post Olympics) because he has an Instagram post in which he draws a raffle among all the followers who leave a comment, which completely distorts the results.

\section{How posts with more reactions are?}

From the 100 posts with the most likes $91 \%$ are from Javier Fernández and the rest are divided equally between Regino Hernández and Queralt Castellet. It has also been observed that almost $80 \%$ of these posts have emoticons and $65 \%$ contain hashtags, while $15 \%$ are videos. The mentions are present in few over $50 \%$ of these posts. 
From the 100 posts with the most comments $70 \%$ are from Javier Fernández, then there is Queralt Castellet with $11 \%$ and the rest are divided among several athletes. In these posts it has been observed that both, emoticons and mentions, are present in few more than $50 \%$ of posts, while in the case of hashtags the situation is similar to the previous one, being present in $66 \%$. From these posts, $18 \%$ are videos.

It is significant the fact that the percentages of videos on the 100 posts with the most likes and the 100 posts with the most comments is almost the double than the percentage of videos that is given in the full sample $(9,4 \%)$. That is, in the case of the 100 most commented videos, the presence of videos in relation to the total of the sample is almost doubled (18\%), and also in the case of likes, where the percentage of videos is higher than the sample in general $(15 \%)$.

\section{DISCUSSION AND CONCLUSIONS}

From these results it can be concluded that, Instagram is revealed as an effective tool for athletes when it comes to generating visibility among their audiences, with a high number of followers and a good ratio in terms of followers / followers in all cases. This seems to indicate that these sports personalities do not need to be regularly active following other accounts, since the greater their sporting success the more followers accumulate, regardless of whether they follow or don't other individuals and the number of posts they publish, as shown by the low correlation between publications and followers.

Regarding the interaction, the differences in results computed through likes and comments are also very marked depending on the previous sporting success of each athlete and keep a direct and obvious correlation with the number of followers, although not so elevated with the number of posts. On the other hand, the engagement data are better in some athletes with fewer followers than in those who are massively followed. This implies that, although in general terms more followers generate more likes and more comments, this increase is not proportional and reaches a point where the incorporation of followers does not generate a significant increase in interaction; this phenomenon could be explained by the fact that the greater the number of followers the more probability there is that among them the number of passive follower's increases. In this section it can also be inferred that the more posts the athlete makes, the greater their engagement, as evidenced by the high correlation between the number of posts and engagement data.

Relating the relationship between type of post, it is striking that images, besides being much more abundant, are less effective than videos when it comes to generating comments and similar effective on generating likes, this could be due Instagram is still understood by athletes as a photography social media. The use of hashtags (\#), mentions (@) or emoticons do not seem to have much incidence in the interaction with audiences; this result is consistent with other previous investigations such as those of Geurin-Eagleman and Burch (2016) or Kim and Hull (2017), which even detect a negative correlation between the use of hashtags and mentions with the number of likes and comments.

The findings of this study in regard to the influence of the Olympic Games in the posts of the athletes on Instagram evidences the importance that a mega sporting event of this nature supposes for the repercussion that the athletes generate in social media. In addition, as expected, athletes who obtained better sporting results (such as getting a medal) saw how the number of likes achieved by their messages were much higher, reaching an improvement of more than $400 \%$ in the case of Regino Hernández. Therefore, athletes should pay special attention to their communication in social media when they participate in an event of these characteristics, trying to achieve the best possible communication results. 
This study is limited to a sample of athletes who have participated in the PyeongChang 2018 Olympic Winter Games and, therefore with a certain notoriety at sport level, so it cannot be extrapolated to the set of elite athletes in Spain. However, the data it provides are an interesting starting point for the development of new studies and the discussion about the effectiveness of Instagram, or other social networks, in terms of generating relationships with fans.

\section{REFERENCES}

Anagnostopoulos, C. et al. (2018). "Branding in pictures: using Instagram as a brand management tool in professional team sport organizations". European Sport Management Quarterly, 18(4), pp. 413438. https://doi.org/10.1080/16184742.2017.1410202

Cano-Tenorio, R., y Paniagua-Rojano, F. J. (2017). "El uso de Twitter por parte de los futbolistas profesionales: contenidos y relaciones con los públicos". Revista Internacional de Relaciones Públicas, 7(13), pp. 101-122. https://doi.org/10.5783/rirp-13-2017-07-101-122

Davies, M., y Mudrick, M. (2017). "Brand management in a niche sport: A case study of an LPGA golfer's use of Instagram". Global Sport Business Journal, 5(1), pp. 1. Available in: http://www.gsbassn.com/Journal/Vol5-1/GSBJ-Vol5-Iss1-Davies-pp1-22.pdf

Geurin-Eagleman, A. N., y Burch, L. M. (2016). "Communicating via photographs: A gendered analysis of Olympic athletes' visual self-presentation on Instagram". Sport management review, 19(2), pp. 133-145. https://doi.org/10.1016/j.smr.2015.03.002

IAB Spain (2018). Estudio anual de redes sociales 2018. Available in: https://iabspain.es/wpcontent/uploads/estudio-redes-sociales-2018_vreducida.pdf

Hull, K., Kim, J. K., y Stilwell, M. (2018). "Fotos de Béisbol: An Examination of the Spanish-language Instagram Accounts of Major League Baseball Teams". Howard Journal of Communications, 30(3), pp. 249-264. https://doi.org/10.1080/10646175.2018.1471756

Kim, J. K., y Hull, K. (2017). "How fans are engaging with baseball teams demonstrating multiple objectives on Instagram". Sport, Business and Management: An International Journal, 7(2), pp. 216 232. https://doi.org/10.1108/sbm-01-2017-0002

Lobillo, G., \& Muñoz, A. (2016). "El papel de las redes sociales en las estrategias de expansión de mercado en los clubes de fútbol españoles. El uso personalizado de Twitter en lengua árabe del Real Madrid CF y FC Barcelona". Trípodos, (38), pp. 195-214. https://doi.org/10.4995/thesis/10251/28212

López de Ayala, M. C., Fernández, J. G., y Catalina-García, B. (2018). "Estrategias de gestión de los clubes de golf de la Comunidad de Madrid en Twitter". Cuadernos. info, (42), pp. 71-84. https://doi.org/10.7764/cdi.42.1304

Olabe, F. (2012). "La comunicación digital del FC Barcelona y del Real Madrid CF y su percepción por los periodistas deportivos". Revista Internacional de Relaciones Públicas, 2(4), pp. 277-298. https://doi.org/10.5783/rirp-4-2012-12-277-298

Pegoraro, A. (2010). "Look Who's Talking-Athletes on Twitter: A Case Study". International journal of sport communication, 3(4), pp. 501-514. https://doi.org/10.1123/ijsc.3.4.501

Pegoraro, A., Comeau, G. S., y Frederick, E. L. (2018). "\# SheBelieves: the use of Instagram to frame the US Women's Soccer Team during \# FIFAWWC". Sport in Society, 21(7), pp. 1063-1077. https://doi.org/10.1080/17430437.2017.1310198

Sotelo, J. (2012). "Deporte y social media: el caso de la Primera División del fútbol español". Historia y comunicación social, 17, pp. 217-230. https://doi.org/10.5209/rev hics.2012.v17.40607 


\section{(c) 1 (i) $(9)$}

This work is licensed under a Attribution-NonCommercial-NoDerivatives 4.0 International (CC BY-NC-ND 4.0). 